Katherine E. Robbins ${ }^{1}$ and Samuel Eddie Davis ${ }^{2}$

\title{
Verification of the ASTM G-124 Purge Equation
}

\begin{abstract}
ASTM G-124 seeks to evaluate combustion characteristics of metals in high-purity ( $>99 \%$ ) oxygen atmospheres. ASTM G-124 provides the following equation to determine the minimum number of purges required to reach this level of purity in a test chamber: $n=-4 / \log _{10}\left(\mathrm{P}_{\mathrm{a}} / \mathrm{P}_{\mathrm{h}}\right)$, where " $\mathrm{n}$ " is the total number of purge cycles required, $\mathrm{P}_{\mathrm{h}}$ is the absolute pressure used for the purge on each cycle and $\mathrm{P}_{\mathrm{a}}$ is the atmospheric pressure or the vent pressure. The origin of this equation is not known and has been the source of frequent questions as to its accuracy and reliability. This paper shows the derivation of the G-124 purge equation, and experimentally explores the equation to determine if it accurately predicts the number of cycles required.
\end{abstract}

KEYWORDS: purge equation, promoted combustion chamber, purge cycles, oxygen concentration, oxygen percentage, Dalton, partial pressures, high purity oxygen atmosphere

\footnotetext{
${ }^{1}$ Student Researcher, Department of Mathematics, Vanderbilt University, 2201 West End Avenue, Nashville, TN 37240 USA

${ }^{2}$ Materials Engineer, Materials Combustion Research Facility, Materials Test Branch, NASA George C. Marshall Space Flight Center, Huntsville, AL 35812 USA
} 


\section{Introduction}

ASTM G-124, "Standard Test Method for Determining the Combustion Behavior of Metallic Materials in Oxygen-Enriched Atmospheres, " was first approved in 1994 and is used internationally for comparisons of the combustion characteristics of various metallic materials. The combustion characteristics that can be evaluated include; lowest burn pressure, highest noburn pressure, and regression rate (apparent burn rate) of the sample, among others. The intent of ASTM G-124 is to evaluate these characteristics of metals in high-purity ( $>99 \%)$ oxygen atmospheres. However, when conducting this test in a laboratory, the only guidance to reach this level of purity in a test chamber, where no greater than $0.01 \%$ of the original atmosphere is allowed to remain, is given by the following equation: $n=-4 / \log _{10}\left(P_{a} / P_{h}\right)$, where " $n$ " is the total number of purge cycles required (rounded up if not an integer), $\mathrm{P}_{\mathrm{h}}$ is the absolute pressure used for the purge on each cycle, and $\mathrm{P}_{\mathrm{a}}$ is the atmospheric pressure or the vent pressure. It is clearly useful to have such an equation because time and resources can be saved by knowing the correct number of purges required to reach the desired concentration of oxygen in a test chamber. However, the validity of this equation has, in the past, been called into question. Applications do exist where a difference of only a few tenths of a percent in the oxygen concentration can yield different combustion behaviors. Therefore, it is important that the origin and limitations of this equation are understood so that the equation can serve as a useful tool when performing testing per ASTM G-124.

\section{Assumptions made:}

This derivation and research utilize the simplifying assumption that the gasses involved behave ideally and compress as ideal gasses compress. This assumption is acceptable because the 
two gasses that dominate the performance of ASTM G-124, namely oxygen and nitrogen, do not behave in a manner that deviates significantly from the manner in which ideal gasses behave under the given conditions.

\section{Experimental}

\section{Test Apparatus}

All testing was conducted in promoted combustion chambers that are used by NASA Marshall Space Flight Center to perform ASTM G-124 testing. Two chambers of different sizes and volumes were used to determine if chamber volume had any effect on the purges. Chamber 1 is a 10 -liter $\left(0.353 \mathrm{ft}^{3}\right)$ promoted combustion chamber, and Chamber 2 is a 17-liter $\left(0.60 \mathrm{ft}^{3}\right)$ promoted combustion chamber.

\section{Procedure}

The procedures performed were identical when either Chamber 1 or Chamber 2 was utilized. Each chamber began the process by being sealed while in normal atmospheric air at ambient temperature and pressure, $\mathrm{P}_{\mathrm{a}}$. First, an initial oxygen concentration reading was taken from the air inside the chamber. Oxygen, as the purge gas, was then allowed to enter the chamber through a series of opening and closings of a valve until the chamber pressure was approximately the same as the desired purge pressure, $\mathrm{P}_{\mathrm{h}}$. The chamber was stagnant for a sufficient length of time to allow the temperature to return to near ambient, pressure to stabilize, and for the gasses to become a homogeneous mixture. This process typically took about three minutes. The 
stabilized pressure was recorded, and the chamber was then vented down to approximately 22.5 psia, or roughly 8 psia above atmospheric pressure. Samples of the gas inside the chamber were periodically removed from the chamber and analyzed by the oxygen analyzer until the oxygen concentration stabilized. This process was performed in order to determine the oxygen concentration of the gas in the chamber. The chamber was then vented down again to $\mathrm{P}_{\mathrm{a}}$, completing the first purge. The same process was repeated until the oxygen concentration either reached $100 \%$ or reached the maximum value that the oxygen analyzer could detect (i.e., when further purges did not increase the oxygen concentration reading on the instrument). After each series of analyses was complete, the chamber was emptied of gas, filled with atmospheric air, and a new purge cycle analysis was begun with the next $\mathrm{P}_{\mathrm{h}}$.

\section{Derivation}

The following symbolism is used throughout this derivation:

$\mathrm{P}_{i}$ - The partial pressure of the chamber gas mixture resulting from gas " $i$ ".

$\mathrm{P}_{\mathrm{a}}$ - The partial pressure of the chamber gas mixture due to the initial chamber gas, normally air.

This is also the lowest pressure that will be witnessed by the test chamber environment during the pressurization and venting cycles. This is typically atmospheric pressure, or the lowest chamber pressure witnessed.

$\mathrm{P}_{\mathrm{h}}-$ The highest pressure that will be witnessed by the test chamber environment during the pressurization and venting cycles. It is the pressure resulting from the mixture of all of the gases inside the chamber.

$\mathrm{X}_{i}$ - The molar ratio of the initial gas " $a$ " of the chamber gas mixture after the " $i^{\text {th" }}$ purge. $n_{i}$ - The number of moles of the original chamber gas remaining after the " $i$ "th" purge. 
This derivation begins by assuming that, even though the assumption does not simplify the derivation, the chamber initially is filled with ambient air at atmospheric pressure and is purged using only oxygen gas (thus the symbolism related to air and oxygen).

This derivation uses two elementary laws of chemistry and physics:

Dalton's Law of partial pressures: $P_{h}=P_{a}+P_{O 2}$

and

Ideal gas law: $\mathrm{PV}=\mathrm{nRT}$

Where $\mathrm{P}=$ Pressure, $\mathrm{V}=$ Volume, $\mathrm{n}=$ Number Moles of Gas, $\mathrm{R}=$ Gas Constant and $\mathrm{T}=$ Temperature

(Note: The Ideal Gas Law is assumed to be applicable, as noted earlier, because ASTM G-124 is almost always conducted using oxygen and nitrogen, which behave very similarly to ideal gases.)

The impetus that leads to this equation in ASTM G-124 is a direct result of the following sentence taken from the test method: "Pressurize and vent the chamber a sufficient number of times to ensure that no more than $0.01 \%$ of the original atmosphere in the vessel remains." This proportion refers to the mole ratio of the original chamber gas versus the final chamber gases, i.e., the ratio of $\mathrm{n}_{\mathrm{a}}$ versus $\mathrm{n}_{\mathrm{h}}$, or $\frac{n_{a}}{n_{h}}$. 
Given that $\mathrm{PV}=\mathrm{nRT}$, or equivalently, $\mathrm{n}=\mathrm{PV} / \mathrm{RT}$, the ratio becomes:

Proportion of air remaining: $\quad \frac{n_{a}}{n_{h}}=\frac{\left(\frac{P_{a} V_{a}}{R T_{a}}\right)}{\left(\frac{P_{h} V_{h}}{R T_{h}}\right)}=\frac{P_{a} V_{a} R T_{h}}{P_{h} V_{h} R T_{a}}$

Since Volume and Temperature will not change, and since $\mathrm{R}$ is the Gas Constant, then the equation simplifies to:

$$
\frac{n_{a}}{n_{h}}=\frac{P_{a}}{P_{h}}=X_{1}
$$

This is convenient since the values of $P a$ and $P h$ can be measured with gauges on the test chamber. Therefore, the mole ratio value can be easily obtained.

\section{Initial conditions}

Start with $\mathrm{n}_{0}$ moles of air at atmospheric (or ambient chamber) pressure, $P_{a}$.

Purges will be at a final, or highest, pressure of $P_{h}$ using $\mathrm{O}_{2}$ gas.

\section{First purge}

Pressurize - then vent to $P_{a}$

Dalton's Law of partial pressures: $P_{h}=P_{a}+P_{O 2}$ 
Ideal gas law: $\mathrm{PV}=\mathrm{nRT}$

Molarity of air after first purge $=X_{1}=\left(P_{a} / P_{h}\right)$

Since the chamber is vented to the original pressure, $\mathrm{P}_{\mathrm{a}}$, and both the temperature and volume of the chamber have remained constant, the total moles of the mixture of gases in the chamber are equal to $\mathrm{n}_{0}$.

Therefore, the moles of air remaining $=n_{1}=n_{\text {total }} X_{1}=n_{0} X_{1}$

\section{Second purge}

Pressurize - then vent to $P_{a}$

The total pressure in the chamber is equal to the partial pressures of the remaining air and the oxygen added during the current purge.

The molarity of air after second purge $=X_{2}=\frac{\left(X_{1} P_{a}\right)}{P_{h}}=\left(P_{a} / P_{h}\right)^{2}$

Again, the total number of moles of gas in the chamber is equal to $\mathrm{n}_{0}$.

Moles of air remaining $=n_{2}=n_{\text {total }} X_{2}=n_{0} X_{2}$

Proportion of air remaining $=\frac{n_{2}}{n_{0}}=X_{2}=\left(P_{a} / P_{h}\right)^{2}$ 
Nth purge

$$
\text { Proportion of air remaining }=\frac{n_{N}}{n_{0}}=X_{N}=\left(P_{a} / P_{h}\right)^{N}
$$

Solving for $N$ :

$$
\begin{aligned}
& X_{N}=\left(P_{a} / P_{h}\right)^{N} \\
& \log \left(X_{N}\right)=\log \left(\left(P_{a} / P_{h}\right)^{N}\right)=N \cdot \log \left(P_{a} / P_{h}\right) \\
& N=\frac{\log \left(X_{N}\right)}{\log \left(P_{a} / P_{h}\right)}
\end{aligned}
$$

When $\mathrm{X}_{\mathrm{N}}=0.01 \%=0.0001$, and $\log$ base 10 is used,

$$
N=\frac{\log _{10}\left(10^{-4}\right)}{\log _{10}\left(P_{a} / P_{h}\right)}=\frac{-4}{\log _{10}\left(P_{a} / P_{h}\right)}
$$

Equation (1) and Equation (2) are themselves valuable since they are more general forms of the Purge Equation and allow for a variety of conditions.

\section{Data and Analysis}

Step by step calculations

In order to look more closely at the data, it is useful to consider each purge individually, especially because of the difficulty in purging at exactly the same $\mathrm{P}_{\mathrm{h}}$ each time. Equation (3) above was modified slightly for the actual experiment. This modification was performed to correct for the inherent errors that would creep into the equation because the initial chamber 
atmosphere is air, with $20.9 \%$ oxygen, and the purge gas was oxygen. The equation, taking into consideration oxygen in both the initial chamber air and purge gas becomes:

$$
G=X_{N} \cdot G_{0}+\left(1-X_{N}\right) \cdot C
$$

Where, $\mathrm{G}$ is the final oxygen concentration,

$\mathrm{G}_{\mathrm{o}}$ is initial oxygen concentration,

$\mathrm{X}_{\mathrm{N}}$ is the proportion of original atmosphere left in the chamber after $\mathrm{N}$ purges, and

$\mathrm{C}$ is the oxygen concentration of the purge gas.

From Eq.1, for a single purge $X_{1}=\left(P_{a} / P_{h}\right)$, so after a single purge:

$$
G=\left(P_{a} / P_{h}\right) \cdot G_{0}+\left(1-\left(P_{a} / P_{h}\right)\right) \cdot C
$$

Equation (5) was used to generate the $\mathrm{O}_{2} \%$ predicted by the purge equation after each single purge. Using this method, a situation where errors would quickly become compounded because of variations in $\mathrm{P}_{\mathrm{h}}$ from purge to purge was avoided. 
TABLE 1 - Purge data from Chamber 1 and 2

\begin{tabular}{|c|c|c|c|c|c|c|c|c|c|}
\hline \multicolumn{5}{|c|}{ Chamber 1} & \multicolumn{5}{|c|}{ Chamber 2} \\
\hline Purge \# & $\mathrm{P}_{\mathrm{a}}$ & $\mathrm{P}_{\mathrm{h}}$ & $\mathrm{O}_{2} \%$ & Predicted $\mathrm{O}_{2} \%$ & Purge \# & $\mathrm{P}_{\mathrm{a}}$ & $P_{h}$ & $\mathrm{O}_{2} \%$ & Predicted $\mathrm{O}_{2} \%$ \\
\hline 0 & & & 20.5 & 20.5 & 0 & & & 20.8 & 20.8 \\
\hline 1 & 14.7 & 82.7 & 88.7 & 85.86 & 1 & 14.82 & 89.82 & 86.8 & 86.85 \\
\hline 2 & 14.7 & 94.7 & 98.1 & 98.24 & 2 & 14.82 & 89.82 & 97.7 & 97.74 \\
\hline 3 & 14.7 & 85.7 & 99.5 & 99.67 & 3 & 14.82 & 95.82 & 99.5 & 99.56 \\
\hline 4 & 14.7 & 88.7 & 99.7 & 99.92 & 4 & 14.82 & 91.82 & 99.8 & 99.84 \\
\hline 5 & 14.7 & 128.7 & 99.8 & 99.97 & 5 & 14.82 & 98.82 & 99.9 & 99.89 \\
\hline 0 & & & 20.5 & 20.5 & 0 & & & 20.8 & 20.8 \\
\hline 1 & 14.76 & 167.76 & 93.7 & 93.01 & 1 & 14.82 & 163.82 & 93.0 & 92.74 \\
\hline 2 & 14.76 & 159.76 & 99.4 & 99.42 & 2 & 14.82 & 173.82 & 99.1 & 99.31 \\
\hline 3 & 14.76 & 164.76 & 99.9 & 99.95 & 3 & 14.82 & 177.82 & 99.7 & 99.83 \\
\hline 4 & 14.76 & 158.76 & 100.0 & 99.99 & 4 & 14.82 & 162.82 & 99.8 & 99.88 \\
\hline 0 & & & 20.5 & 20.5 & 0 & & & 20.8 & 20.8 \\
\hline 1 & 14.76 & 280.76 & 96.3 & 95.82 & 1 & 14.82 & 268.82 & 95.6 & 95.54 \\
\hline 2 & 14.76 & 270.76 & 99.8 & 99.80 & 2 & 14.82 & 266.82 & 99.5 & 99.66 \\
\hline 3 & 14.76 & 274.76 & 100.0 & 99.99 & 3 & 14.82 & 269.82 & 99.7 & 99.88 \\
\hline 0 & & & 20.5 & 20.5 & 0 & & & 20.7 & 20.7 \\
\hline 1 & 14.76 & 441.76 & 97.7 & 97.34 & 1 & 14.79 & 441.79 & 97.2 & 97.06 \\
\hline 2 & 14.76 & 451.76 & 99.9 & 99.92 & 2 & 14.79 & 408.79 & 99.7 & 99.80 \\
\hline 3 & 14.76 & 445.76 & 100.0 & 100.00 & 3 & 14.79 & 416.79 & 99.8 & 99.89 \\
\hline 0 & & & 20.5 & 20.5 & 0 & & & 20.7 & 20.7 \\
\hline
\end{tabular}




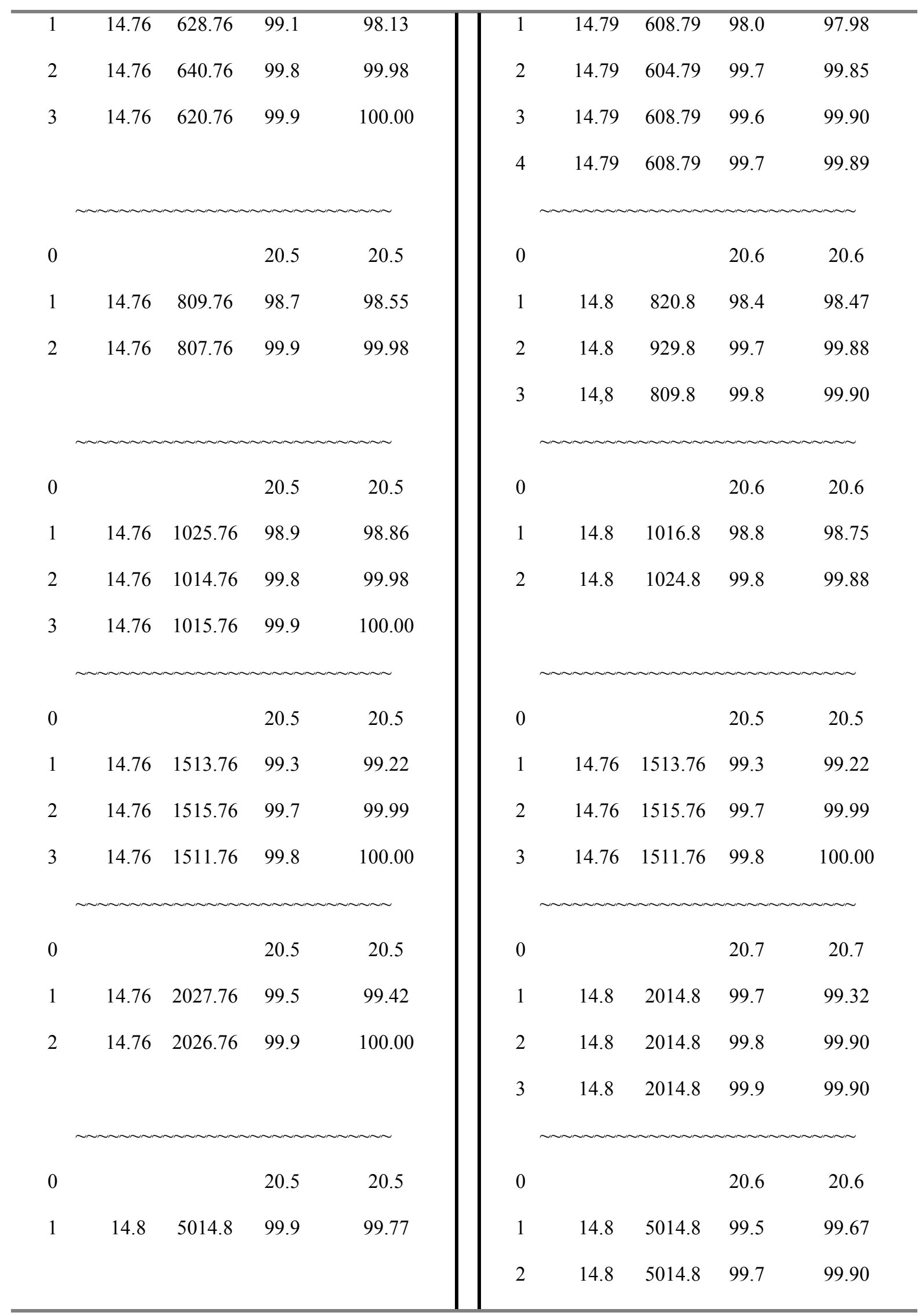




\begin{tabular}{l|l|lllll}
\hline & 3 & 14.8 & 5014.8 & 99.8 & 99.90 \\
\hline
\end{tabular}

\section{Graphs}

The graphs below show a plot of the actual $\mathrm{O}_{2} \%$ and the predicted $\mathrm{O}_{2} \%$ vs. the purge number. The actual versus predicted points align very closely together. The average difference between these points is reported as 'avg. D' in Table 2 for Chamber 1 and Table 3 for Chamber 2.
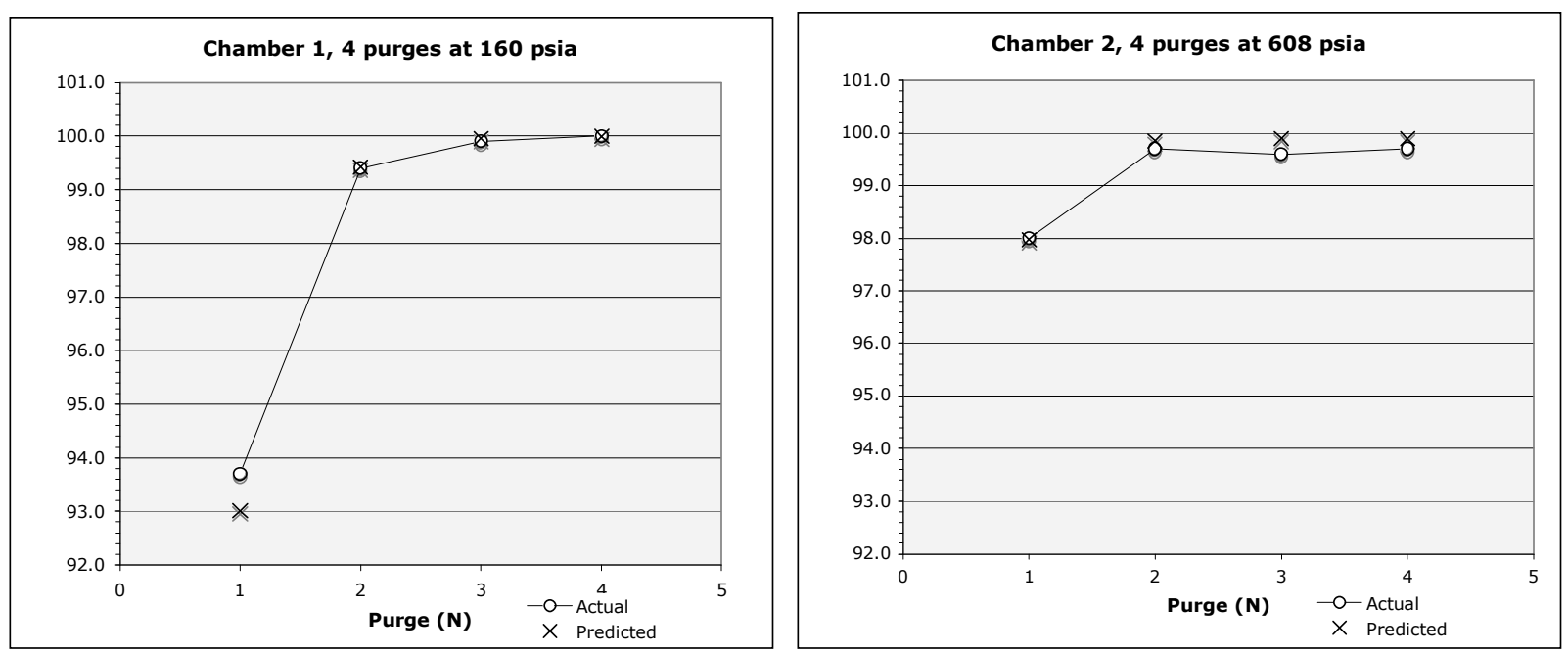

\section{Results}

Below is a summary of the data obtained for the two chambers. The average $\mathrm{P}_{\mathrm{h}}$ over the series of purges is shown for convenience. However, the average $\mathrm{P}_{h}$ was not used for any calculations since the purges were analyzed individually, step by step. An asterisk is present if the actual number of purges required to reach the final $\mathrm{O}_{2} \%$ was more than the number predicted 
by the purge equation. The column 'avg. D' lists the average difference between the actual and the predicted $\mathrm{O}_{2} \%$ per purge.

TABLE 2 - Summary for Chamber 1

\begin{tabular}{ccccccccc}
\hline $\begin{array}{c}\mathrm{P}_{\mathrm{a}}, \\
\text { psia }\end{array}$ & avg. $\mathrm{P}_{\mathrm{h}}$, & Purges & Initial & Final & Purges & avg. $\mathrm{D}$, & $\mathrm{D}<0.1 \%$ & $\mathrm{D}<0.2 \%$ \\
\hline 14.7 & 96.1 & 5 & 20.5 & 99.8 & $4^{*}$ & $0.7080^{3}$ & No & No \\
14.76 & 162.76 & 4 & 20.5 & 100.0 & 4 & 0.1900 & No & Yes \\
14.76 & 275.43 & 3 & 20.5 & 100.0 & 4 & 0.1600 & No & Yes \\
14.76 & 446.43 & 3 & 20.5 & 100.0 & 3 & 0.1300 & No & Yes \\
14.76 & 630.09 & 3 & 20.5 & 99.9 & $2 *$ & 0.4167 & No & No \\
14.76 & 808.76 & 2 & 20.5 & 99.9 & 2 & 0.1150 & No & Yes \\
14.76 & 1018.76 & 3 & 20.5 & 99.9 & $2 *$ & 0.1067 & No & Yes \\
14.76 & 1513.76 & 3 & 20.5 & 99.8 & $2 *$ & 0.1900 & No & Yes \\
14.76 & 2027.26 & 2 & 20.5 & 99.9 & 2 & 0.0900 & Yes & Yes \\
14.8 & 5014.80 & 1 & 20.5 & 99.9 & 2 & 0.1300 & No & Yes \\
\hline
\end{tabular}

TABLE 3 - Summary for Chamber 2

\begin{tabular}{ccccccccc}
\hline $\mathrm{P}_{\mathrm{a}}$, & avg. $\mathrm{P}_{\mathrm{h}}$, & Purges & Initial & Final & Purges & avg. $\mathrm{D}$, & $\mathrm{D}<0.1 \%$ & $\mathrm{D}<0.2 \%$ \\
psia & psia & & $\mathrm{O}_{2} \%$ & $\mathrm{O}_{2} \%$ & predicted & $\%$ & $?$ & $?$ \\
\hline 14.82 & 93.22 & 5 & 20.8 & 99.9 & $4^{*}$ & 0.0400 & Yes & Yes \\
14.82 & 169.57 & 4 & 20.8 & 99.8 & $3 *$ & 0.1700 & No & Yes \\
14.82 & 268.49 & 3 & 20.8 & 99.7 & $2 *$ & 0.1333 & No & Yes \\
14.79 & 412.46 & 3 & 20.7 & 99.8 & $2 *$ & 0.1100 & No & Yes \\
\hline
\end{tabular}

${ }^{2}$ Purges predictions were obtained by rearranging equation (4) to solve for $X_{N}$, then substituting into equation (2).

${ }^{3}$ The high value for $\mathrm{D}$ at low pressures in Chamber 1 may be a result of poor mixing, since less turbulence has been observed in Chamber 1. 


\begin{tabular}{lcccccccc}
\hline 14.79 & 607.79 & 4 & 20.7 & 99.7 & $2^{*}$ & 0.1650 & No & Yes \\
14.80 & 853.47 & 3 & 20.6 & 99.8 & $2^{*}$ & 0.1167 & No & Yes \\
14.80 & 1020.80 & 2 & 20.6 & 99.8 & 2 & 0.0650 & Yes & Yes \\
14.80 & 1514.80 & 3 & 20.5 & 99.6 & $2^{*}$ & 0.3733 & No & No \\
14.80 & 2014.80 & 3 & 20.7 & 99.9 & $2 *$ & 0.1600 & No & Yes \\
14.80 & 5014.80 & 3 & 20.6 & 99.8 & $2 *$ & 0.1567 & No & Yes \\
\hline
\end{tabular}

The summary table above demonstrates that the purge equation typically did not predict the number of purges exactly. However, the prediction was almost always within one purge of the actual number of purges. One factor affecting the measured values is that the available oxygen analyzer did not have enough accuracy to allow $\mathrm{X}_{\mathrm{N}}=0.01 \%$. The oxygen analyzer only displayed one decimal place, so the smallest $X_{N}$ that could be detected was $0.1 \%$ and this may have changed smaller inaccuracies into larger ones in later purges. Also, the average difference from the predicted oxygen percentage was not normally within $0.1 \%$, but was typically within $0.2 \%$.

\section{Discussion of Uncertainties}

\section{Oxygen Analyzer and Purge Gas Purity}

The largest contributors of uncertainty in this experiment were the inherent inaccuracies of the oxygen analyzer and the true oxygen concentration of the purge gas. The oxygen analyzer only displayed to one-tenth of one percent oxygen concentration. This created inaccuracies in that small changes of $\mathrm{O}_{2} \%$ in the chamber could not be determined. These inaccuracies compounded as purges were repeated. Also, many of the purge cycles had readings that were 
above $99.0 \%$ and only one significant digit could change. The purity of the purge gas itself is also an issue because gas purity affects many calculations. The best available gas supply was only labeled by the vendor as " $>99.6 \%$." For the calculations made here, an assumption was made that the purity of the purge gas was $100 \%$. An assumption of $100 \%$ is required because running the purge gas though the oxygen analyzer typically produced readings of $\sim 99.9 / 100 \%$. However, it is possible that the purity was less at times. This would explain why purges in Chamber 1 could often reach $99.9 \%$ or $100 \%$, while purges in Chamber 2 could only reach $99.8 \%$ or $99.9 \%$.

\section{Multiple Purges}

Utilizing chambers that are designed to purge at high pressures often makes it difficult to stop the purge at an exact peak purge pressure, such as 80 psia. Because of this, each purge was analyzed individually rather than assuming a constant $\mathrm{P}_{\mathrm{h}}$ over a series of purges. By using this method, deviations from the purge equation could be determined without the introduction of additional errors when the $\mathrm{P}_{\mathrm{h}}$ values are not constant. This is a beneficial means of analysis, but, in actual applications, these small, individual errors would be compound though multiple purges. It should be noted that, in actual application, more purges lead to greater overall errors.

\section{Pressure and Temperature}

The test chamber temperature could not always be held at a constant level during the purge cycles, which led to other inherent compounded errors. Most notably, whenever purge gas was added to a chamber, both the pressure and the temperature would increase significantly. 
Even though additional time was added to allow the temperature to drop back to normal prior to taking pressure readings, the temperature differential may have caused variations in the pressure readings, especially for higher pressures purges in which the temperature increases were more substantial.

\section{Conclusions}

The purge equation provides a good rough estimate for the number of purges required to reach a given gas concentration. In this study, the actual number of purges was within one purge of the number predicted by the purge equation in nineteen out of twenty independent tests. The equation itself holds up well with resulting deviations that are small, typically within $0.2 \%$ of the actual oxygen percentage for each purge. If accuracy to within a few tenths of one-percent is desired, then this test method requires using an accurate, calibrated oxygen analyzer to determine the oxygen concentration at each step. However, the test method given by ASTM G-124 rarely requires this level of accuracy. Therefore, the purge equation is a valuable tool that can be used to determine the number of purge cycles that are required to be performed prior to igniting a test sample in an ASTM G-124 test. 